\title{
OLHARES INFANTIS: O BAIXO DESEMPENHO ACADÊMICO, A ESCOLA E A FAMÍLIA
}

\author{
PERCEPTIONS OF CHILDREN: LOW ACADEMIC PERFORMANCE, SCHOOL AND \\ FAMILY
}

\author{
Gabriela Maffei MOREIRA- MALAGOLLI ${ }^{1}$ \\ Keila Hellen Barbato MARCONDES ${ }^{2}$ \\ Luciana Ponce Bellido GIRALDI ${ }^{3}$
}

RESUMO: Apreender as percepções das crianças é um desafio para familiares, professores e pesquisadores. Cientes disso, este artigo foi o resultado de três pesquisas desenvolvidas nos anos de 2006 e 2010 e tem como objetivo apropriar-se de discursos de crianças/alunos da $4^{\circ}$ série $/ 5^{\circ}$ ano do Ensino Fundamental para compreender como concebiam e vivencivam situações de baixo desempenho escolar. A partir da Perspectiva Bioecológica do Desenvolvimento Humano, foram organizadas entrevistas semi-estruturadas com crianças. Os resultados apontaram que as crianças que participaram dos três estudos entendiam a família enquanto ponto de apoio, suporte e afeto. Reconheceram a figura da professora, destacando o relacionamento afetivo que possuiam com ela. Além disso, também revelaram sentirem-se culpadas por suas dificuldades de aprendizagem, manifestando angústia e tristeza. É preciso atentar para a trajetória escolar da criança, para impedir que ela chegue no $5^{\circ}$ ano com defasagens ou mesmo que adquira a concepção de que o percurso da escolarização é penoso.

PALAVRAS-CHAVE: Infância. Baixo desempenho escolar. Ensino Fundamental.

ABSTRACT: Seizing children's perceptions is a challenge for family members, teachers and researchers. Aware of this, this article was the result of three researches developed in the years 2006 and 2010 and aims to appropriate discourses of children / students of the 4th grade / 5th year of Elementary School to understand how they conceived and experienced situations of low performance School. From the Bioecological Perspective of Human Development, semi-structured interviews with children were organized. The results showed that the children who participated in the three studies understood the family as a point of support, support and affection. They recognized the figure of the teacher, highlighting the affective relationship they had with her. In addition, they also revealed feeling guilty about their learning difficulties, expressing anguish and sadness. Attention must be paid to the child's educational trajectory in order to prevent the child from reaching the 5th grade with lags or even to acquire the idea that the course of schooling is painful.

KEYWORDS: Childhood. Low school performance. Elementary school.

\footnotetext{
${ }^{1}$ Universidade Estadual Paulista (Unesp), Faculdade de Ciências e Letras. Araraquara - SP - Brasil. Doutora pelo Programa de Pós-graduação em Educação Escolar. E-mail: gabymaffei@ yahoo.com.br

${ }^{2}$ Universidade Estadual Paulista (Unesp), Faculdade de Ciências e Letras. Araraquara - SP - Brasil. Doutora pelo Programa de Pós-graduação em Educação Escolar. E-mail: keilamarcondes@ yahoo.com.br

${ }^{3}$ Universidade Estadual Paulista (Unesp), Faculdade de Ciências e Letras. Araraquara - SP - Brasil. Doutora pelo Programa de Pós-graduação em Educação Escolar. E-mail: luluponce@ gmail.com
} 


\section{Introdução}

A infância é considerada como um momento importante do desenvolvimento humano. Contudo, compreendê-la por meio dos olhares dos sujeitos, que estão vivenciando esse momento, apresenta-se como uma preocupação recente nas pesquisas.

Segundo Sarmento (2007), os estudos na área das ciências sociais, principalmente na sociologia, durante muito tempo convergiram para a orientação de que a criança seria um objeto destinatário dos processos de socialização primária e secundária, ou seja, internalizavam os valores, hábitos, ideias e normas do seu grupo social e as reproduziam, sendo sujeitos passivos, "tabulas rasas".

As teorias da sociologia tradicional fortaleciam a ideia da infância enquanto fardo social, fase de total dependência da criança para o adulto. Müller e Carvalho (2010) afirmam que tal concepção dificulta a compreensão das relações estabelecidas entre os adultos e crianças, já que a socialização acaba sendo concebida como uma via de mão única, partindo do adulto/a para a criança.

É com o surgimento dos estudos da Sociologia da Infância iniciados na década de 1990 que tais concepções passam a sofrer modificações lentas, compreendendo as crianças como sujeitos ativos, produtos e produtoras de cultura, as quais estão inseridas no mundo e sofrem influência do mesmo, contudo, não sendo passiva nesse processo.

Apesar da gradual alteração desse paradigma, ainda se constata no campo acadêmico a realização de pesquisas "sobre as crianças" e "para as crianças", porém poucas vezes "junto a ela" e "sobre a visão dela", ou seja, conhecer suas vivências e cultura.

Nesse estudo, pretende-se focar as percepções das crianças sobre as suas vivências relacionadas ao baixo desempenho escolar. Justifica-se que no campo acadêmico há uma tendência nas pesquisas sobre a temática em focalizar concepções e vivências de professores e familiares sobre as "possíveis causas" deste desempenho (MONTEIRO, 2000; CHECHIA, 2002; PEREIRA, 2005). Poucas são as pesquisas que buscaram os sentimentos e concepções diretamente com os sujeitos que vivenciam essa situação, ou seja, as crianças.

A importância de se conhecer as concepções, vivências e sentimentos infantis em estudos referentes à temática do baixo desempenho acadêmico é salientada por Patto (1996) ao afirmar que estes sujeitos estavam ausentes em estudos sobre evasão, repetência e fracasso escolar, o que as reduziria: 
[...] a números frios e impessoais, que acabam por insensibilizar a todos para o drama humano que os números escondem, acostumando-nos à existência de um contingente crônico de repetentes e excluídos da rede pública de ensino fundamental. (PATTO, 1996, p. 4).

Ao ouvir as crianças, não se compreende somente seu mundo, mas também o mundo adulto que as cercam de acordo com suas interpretações. Para tanto, é necessário abandonar a visão hierárquica do adulto e reconhecer a criança como sujeito ativo na pesquisa e em seu viver, cientes de que escutá-la permite construir um conhecimento sobre sua realidade.

Assim como, conceber a criança como objeto da pesquisa e, ao mesmo tempo, sujeito não significa que se restringirá a olhar a infância descolada no contexto da qual faz parte. Segundo Moraes (2004) a infância não é um dado natural, mas sim, um dado social, historicamente construído segundo os interesses de uma dada sociedade e que exprime as aspirações, postuladas num determinado tempo, e as recusas sociais e dos adultos que nela vivem.

Assim sendo, as culturas infantis não são totalmente redutíveis à cultura produzida pelos adultos, mas também não produzem culturas descontextualizadas, descoladas, num vazio social (DELGADO; MÜLLER, 2005). Ou seja, são influenciadas e influenciam; reproduzem, criam e recriam. Uma vez que a infância é uma construção histórica, cultural e social é necessário compreender essas crianças em seus ambientes, analisando as influências que sofrem e que exercem nesses contextos.

Então, conceber as crianças como sujeitos ativos permite compreender suas experiências e concepções interligadas aos seus contextos sociais e culturais. Como afirma Borba (2006) as infâncias e as crianças devem ser estudadas em sua alteridade, de forma direta e participativa, não por meio de outras instituições sociais, como a família e a escola. Com esse intuito, o presente estudo tem como objetivo apropriar-se de discursos de crianças/alunos para apreender como concebem e vivenciam situações de baixo desempenho escolar.

Destaca-se que este texto entende que o objetivo da escolarização é a aquisição de conhecimentos construídos socioculturalmente. Pensando nas etapas iniciais, as aquisições estão voltadas para as áreas de leitura, escrita e cálculos elementares. Assim sendo, o baixo desempenho escolar se traduziria como uma resposta inadequada a esse processo de aquisição, com baixa apreensão dos conhecimentos esperados para essa fase (CARVALHO, 2000), concepção essa adotada neste estudo. 
Há que se enfatizar que o baixo desempenho acadêmico é multideterminado, ou seja, ao longo da trajetória de desenvolvimento do indivíduo as suas propriedades específicas interagem com o ambiente e essa interação produz modificações e constâncias em seu desenvolvimento e aprendizagem (ASSIS, 1985; CARVALHO, 2000; CHECHIA, 2002; GARCIA, 2003; SANTOS, 2002).

Nesse sentido, o baixo desempenho escolar é concebido como sendo influenciado por diversos fatores, que podem estar ligados à sociedade, à escola e aos alunos. Sendo assim, levam em conta aspectos ligados a essas três perspectivas, a fim de construir uma visão complexa do problema.

No presente estudo, especificamente, adota-se a visão de que as causas do baixo desempenho escolar são multideterminadas e peculiares em cada caso. De acordo com Assis (1985), o desempenho escolar deve ser pensado como uma:

Multiplicidade de fatores envolvidos [...] a variedade de aspectos abordados que vão desde as variáveis físicas como determinantes neurológicos e nutricionais, até variáveis sociais, passando pelos aspectos psicológicos, pedagógicos e institucionais. (ASSIS, 1985, p. 7).

Deve-se ressaltar que, apesar de adotar a visão das interrelações de fatores que influenciam o desempenho escolar, tem-se a consciência da impossibilidade do aprofundamento de cada fator específico em uma mesma pesquisa. Como salienta Assis (1985), realizar um estudo muito amplo, que aborde ao mesmo tempo fatores físicos, nutricionais, psicológicos, pedagógicos e institucionais, além de ser inviável, leva à perda em profundidade.

Devido aos diferentes contextos que podem ser envolvidos na análise do baixo desempenho escolar, adotar-se-á a concepção contextual de desenvolvimento humano, que pode ser definida como sendo o produtor e o produto dos processos de interação, que devem ser recíprocos, entre o ser humano biopsicologicamente ativo, e os múltiplos contextos em que o indivíduo está inserido. Os processos são compreendidos como sendo as relações entre o organismo e contexto. A concepção contextual de desenvolvimento humano tem adquirido importância principalmente nas últimas décadas (SIGOLO, 2001, 2002).

O contexto, para Bronfenbrenner (1996), é concebido como sendo uma série de estruturas encaixadas, uma dentro da outra, diferenciando-se em quatro níveis: micro-, meso-, exo- e macrossistema. Essas influências ambientais formam um "pano de fundo" para a compreensão dos processos psicológicos, permitindo assim um melhor entendimento deles. 
Segundo Bronfenbrenner e Ceci (1994, p. 572):

O desenvolvimento humano acontece através de processos de interação recíproca progressivamente mais complexa entre um ativo organismo biopsicológico em evolução e as pessoas, objetos e símbolos no seu ambiente imediato.

De acordo com essa perspectiva, indivíduo e ambiente são partes inseparáveis de um todo. A opção por esta perspectiva teórica respalda-se na consideração dos seguintes fatores: a multiplicidade de influências que recaem sobre a pessoa, o sentido de bidirecionalidade de influências, a realidade não imediatamente presente e o reconhecimento de alterações no contexto histórico-social ao longo da trajetória de vida como fatores determinantes do processo de desenvolvimento humano.

A preocupação desta pesquisa, em compreender as percepções das crianças, centra-se no microssistema, composto pelo contexto família e escola, que consiste em um padrão de atividades, papéis e relações interpessoais experienciados pela pessoa em desenvolvimento num dado ambiente, com características físicas e materiais específicos, no entanto, não há como esquecer-se que para se compreender o microssistema, deve-se estar atento para as influências do meso, exo e macrossistema.

\section{Metododologia}

\section{Participantes}

Participaram desta pesquisa quinze crianças que frequentavam os anos finais do Ensino Fundamental nos anos de 2006 e 2010, em três escolas públicas, localizadas em municípios do interior do Estado de São Paulo, sendo duas crianças do Município A (uma menina e um menino), sete crianças do Município B (três meninas e três meninos) e seis crianças do Município C (quatro meninos e duas meninas). A idade das crianças variava entre 10 e 12 anos, sendo que três apresentavam histórico de reprovação escolar e uma delas histórico de abandono.

Abaixo segue o quadro de caracterização dos sujeitos dos três Municípios participantes da pesquisa ${ }^{4}$.

${ }^{4}$ Legenda: $\mathrm{C}=$ crianças; $\mathrm{I}=$ Idade; $\mathrm{A}=$ Ano; H.E. = Histórico Escolar; C.R. = com reprovação; S.R. = sem reprovação; A.E. = abandono escolar; E.I. = frequência à Educação Infantil; C.F. = Constituição Familiar; P.C. = Pessoas que moram na casa. 
Quadro 1: Caracterização dos alunos que participaram do estudo

\begin{tabular}{|c|c|c|c|c|c|c|c|}
\hline & Crianças & Idade & $\begin{array}{c}\text { Ano } \\
\text { Série }^{5}\end{array}$ & $\begin{array}{l}\text { Hist. } \\
\text { Esc. }\end{array}$ & $\begin{array}{c}\text { Freq. a } \\
\text { Educ. } \\
\text { Inf. }\end{array}$ & $\begin{array}{c}\text { Const. } \\
\text { Familiar }\end{array}$ & $\begin{array}{c}\text { Quantas } \\
\text { pessoas } \\
\text { moram na } \\
\text { casa }\end{array}$ \\
\hline \multirow{2}{*}{$\begin{array}{c}\text { Município } \\
\text { A } \\
\text { Giraldi } \\
\text { (2010) }\end{array}$} & Agenor & 12 & $5^{\circ}$ & $\begin{array}{l}\text { C.R. } \\
\text { A.E. }\end{array}$ & SIM & Ampliada & 10 \\
\hline & Aurora & 10 & $5^{\circ}$ & S.R. & SIM & Reconstituída & 9 \\
\hline \multirow{7}{*}{$\begin{array}{c}\text { Município } \\
\text { B } \\
\text { Moreira } \\
\text { (2006) }\end{array}$} & Alice & 10 & $4^{a}$ & S.R. & SIM & Reconstituída & 4 \\
\hline & Aline & 11 & $4^{\mathrm{a}}$ & S.R. & SIM & Nuclear & 4 \\
\hline & Daniel & 12 & $4^{a}$ & S.R. & SIM & Reconstituída & 3 \\
\hline & Denise & 10 & $4^{a}$ & S.R. & SIM & Ampliada & 6 \\
\hline & Douglas & 12 & $4^{a}$ & S.R. & SIM & Nuclear & 4 \\
\hline & Denis & 11 & $4^{a}$ & S.R. & SIM & Ampliada & 4 \\
\hline & Denílson & 11 & $4^{a}$ & C.R. & SIM & Reconstituída & 4 \\
\hline \multirow{6}{*}{$\begin{array}{l}\text { Município } \\
\text { C } \\
\text { Marcondes } \\
(\mathbf{2 0 0 6 )}\end{array}$} & Ramon & 10 & $4^{a}$ & S.R. & SIM & Ampliada & 4 \\
\hline & Gustavo & 10 & $4^{a}$ & S.R. & SIM & Nuclear & 4 \\
\hline & Talita & 10 & $4^{a}$ & S.R. & SIM & Matrifocal & 5 \\
\hline & Igor & 11 & $4^{a}$ & C.R. & SIM & Nuclear & 3 \\
\hline & Luana & 10 & $4^{a}$ & S.R. & SIM & Nuclear & 6 \\
\hline & Weslei & 10 & $4^{a}$ & S.R. & SIM & Ampliada & 7 \\
\hline
\end{tabular}

Fonte: Elaboração própria.

\section{Instrumentos de coleta de dados}

Para a coleta de dados foram realizadas entrevistas semi-estruturadas com as crianças, as quais ocorreram conforme um procedimento utilizado na área da Psicopedagogia, em que é chamado de "hora lúdica", que se configura como um processo de observação, intervenção e de pesquisa preparado para as crianças expressarem seus sentimentos, emoções ou mesmo dificuldades e facilidades no processo de aprendizagem.

Os roteiros de entrevistas eram compostos por questões que visavam obter informações sobre o desempenho escolar das crianças, suas concepções, vivências e percepções sobre o suporte da escola às suas dificuldades. Puderam ser acrescidos de outras perguntas que por ventura poderiam vir a surgir, de acordo com a dinâmica estabelecida entre

${ }^{5} \mathrm{Na}$ pesquisa de Marcondes (2006) e Moreira (2006) o último ano do Ensino Fundamental era intitulado de $4^{\text {a }}$ série, porém a lei $\mathrm{n}^{\circ} 11.274$ alterou a duração deste nível de ensino de oito para nove anos e, portanto, em Giraldi (2010) o último ano do Ensino Fundamental I passou a ser intitulado de $5^{\circ}$ ano.

${ }^{6}$ Para mais informações ver Giraldi (2010), Marcondes (2006) e Moreira (2006). 
entrevistador e entrevistado (BIASOLI-ALVES, 1998; LAVILLE; DIONNE, 1999; MANZINI, 1990).

\section{Procedimentos}

A coleta de dados ocorreu em dois momentos distintos: em 2010 no município A e em 2006 no Município B e C. Todos os municípios estão localizados no interior do Estado de São Paulo com distância entre eles de aproximadamente 100 quilômetros.

Os sujeitos que fizeram parte desta pesquisa cursavam o último ano do Ensino Básico I. A coleta de dados iniciou-se após a autorização da Secretaria de Educação do Munícipio A e das diretoras das escolas pesquisadas no Município B e C. Em seguida, foi realizada uma conversa com as docentes responsáveis por tais anos escolares e houve a indicação dos alunos que apresentavam baixo desempenho acadêmico.

Após a indicação, os responsáveis foram contatados para esclarecimento dos objetivos das pesquisas e, após autorização, foi realizada uma conversa com as crianças sobre a realização do estudo. A coleta de dados somente foi iniciada após o preenchimento dos Termos de Consentimento Livre e Esclarecido pelas docentes e pelos responsáveis dos alunos.

Para a coleta, foram organizadas entrevistas que pudessem atender as singularidades da infância e, por isso, recursos lúdicos foram empregados. As conversas ocorreram no ambiente escolar em horários estipulados pelas docentes, no caso das pesquisas do município A e C, e nas casas das crianças no caso do Município B. Todas as entrevistas foram gravadas e transcritas de forma integral pelas próprias pesquisadoras.

\section{Análise de dados}

Para a análise dos dados foi adotada a abordagem qualitativa/objetiva, que possibilitou a apreensão multidimensional das variáveis estudadas, em seu contexto natural, contribuindo para o estabelecimento de inferências, atribuição dos significados e interpretação do comportamento. Essa abordagem ainda pressupõe o contato direto do observador com o ambiente, captando os diferentes significados de experiências vividas pelos sujeitos da pesquisa (BIASOLI-ALVES, 1998).

As três pesquisas (GIRALDI, 2010; MOREIRA, 2006; MARCONDES, 2006), discutiram os dados coletados a partir de categorias. Destas, foi identificado o que era comum 
aos três estudos. De tal modo, sob o critério da proximidade, sistematizou-se os seguintes eixos de análise:

- Papel de aluno: avaliações sobre os desempenhos acadêmicos;

- Histórico de baixo desempenho escolar;

- Causa do baixo desempenho escolar;

- Sentimentos experienciados frente ao baixo desempenho acadêmico;

- Atitudes tomadas pelas crianças frente ao baixo desempenho;

- Atitudes tomadas pelos familiares frente ao baixo desempenho acadêmico;

- Atitudes tomadas pelos professores perante o baixo desempenho acadêmico.

\section{Resultados e discussão}

O presente estudo não se centrou somente nas questões objetivas, ou seja, observáveis e possíveis de serem descritas, mas também nas expectativas, vivências e experiências das crianças que participaram desse processo. Como afirma Bronfenbrenner (2011, p. 44),

[...] as características cientificamente relevantes de qualquer contexto para o desenvolvimento humano incluem não apenas suas condições objetivas, mas também a maneira pela quais essas são experienciadas subjetivamente pelas pessoas que vivem nesse ambiente.

É importante salientar que, para a perspectiva Bioecológica, não irá se considerar as questões objetivas ou subjetivas mais ou menos influentes no desenvolvimento humano, mas irá compreendê-las como forças interdependentes e que se influenciam mutuamente (BRONFENBRENNER, 2011).

Assim sendo, de acordo com a percepção infantil o papel de aluno está relacionado basicamente com a aprendizagem acadêmica e o respeito às normas e regras da instituição escolar.

Evidencia-se uma correlação do papel de aluno e posicionamento passivo deste diante da aprendizagem. As crianças salientam que é dever do(a) aluno(a) copiar e aprender tudo o que for transmitido pela professora, sem questionamentos ou tentativas de estabelecer uma relação bidirecional. Segundo Luana (Município C) as crianças "Tem que vim na escola, se arrumá, vir pra escola, sentá, lê, aprende a lê, escrevê". Na mesma perspectiva, Aline 
(Município B) relatou: "Ser aluno? Aprender...pra passar de ano. [...] Ir na aula e prestar muita atenção".

O papel da escola estava atrelado ao papel do aluno, seria o ensino e a aprendizagem da leitura, escrita e do cálculo. Para alguns a função da escola estava arrolada a ficar "esperto", ou porque sem escola o conhecimento acumulado, por meio da leitura, escrita e dos números não seria adquirido por eles: "Ninguém ia saber ler, escrever, nem fazer continha, não ia saber nada." (Aurora - Município A). O que pensa também Denílson (Município B): "Porque você aprende mais e pode depois fazer alguma coisa. Pode trabalhar em algum lugar."

É visível nos relatos das crianças a internalização da concepção cultural e historicamente construída sobre a infância, ou seja, aquele que não fala e de aluno, o ser sem luz, dependente do outro e ilegítimo (SARMENTO, 2005). Essa concepção cristalizada faz com que se compreenda que "[...] o modo de ser aluno é a maneira natural de ser criança; representamos os dois conceitos como se os dois conceitos fossem equivalentes." (GIMENOSÁCRISTAN, 2005, p.15).

Quanto às avaliações sobre os desempenhos acadêmicos, as crianças salientaram que estão aquém do esperado para sua etapa de escolarização, relatando que apresentam dificuldades em aprender determinados conteúdos.

Inclusive, entre os estudantes havia comentários com relação aos desempenhos alheios, como pode ser visto na fala de Aline (Município B): "Ela só não passou de ano, porque ela nem ligava pras coisas. Ela não tava nem aí. Tinha lição, ela não fazia. Só pensava em outra coisa."

Vale a pena destacar, sobre as análises dos desempenhos estabelecidas pelos próprios alunos que, apesar de Aurora (Município A), reconhecer que não conseguia fazer as contas de matemática sozinha, ela se considerava uma aluna mediana, porque, uma boa aluna conseguiria realizar as contas que ela não sabia. Não se avaliava como uma aluna com baixo desempenho, porque não brigava com os colegas de escola. Comparando-se com uma aluna com alto desempenho, ela relatou: "Ela sabe escrever muito mais do que eu, ela sabe responde a resposta e eu não consigo." (Aurora - Município A).

Também foi possível notar em Giraldi (2010), que mesmo reconhecendo as dificuldades com o dominio de conteúdos, outros caminhos eram encontrados para se auto valorizarem, "Não faço bagunça. [...] Não vou pra diretoria." (Agenor - Município A), portanto ele dizia se considerar um aluno com alto desempenho e, assim não se enquadravam nas ideias postas por outros estudos, como o de Carneiro, Martinelli e Sisto (2003), ao 
afirmarem que estudantes, entre nove e dez anos de idade, com dificuldades na aprendizagem da escrita apresentavam baixo auto-conceito geral e escolar.

Conforme Senos (1997) há entre alguns alunos, principalmente, e em média a partir dos 12 anos de idade, um processo de mediação dos baixos resultados, fazendo com que essas informações não atinjam a auto-estima ou o auto-conceito dos mesmos utilizando-se para isso das relações entre os pares, nas quais são criadas estratégias de proteção da auto-estima a partir do grupo no qual se integra, rompendo com uma possível relação direta entre autoestima e resultados escolares.

Contudo, a análise dos desempenhos escolares nem sempre se configuram desta maneira. Para alguns, a trajetória escolar das crianças é descrita como apresentando um histórico de baixo desempenho escolar. Observa-se nos relatos a indicação de que havia dificuldades na aprendizagem dos conteúdos escolares, na maioria dos casos, desde o primeiro ano do Ensino Fundamental, como afirma Weslei (Município C): "Foi na primeira [...] é na primeira (que iniciaram as dificuldades) [...] que eu num conseguia escrevê. Eu num tinha aprendido ainda [...]". As crianças relatavam que se sentiam frustradas perante sua escolarização, na medida em que enfrentavam dificuldades há alguns anos.

Apesar de apresentarem um desempenho inadequado desde o início do ciclo I do Ensino Fundamental, as crianças avaliavam que seus resultados escolares foram melhorando a cada novo ano letivo. Os progressos são analisados de forma positiva, mas não encobrem, para os alunos, a percepção de um desempenho abaixo do esperado.

Para muitos, há uma ciência em relação à própria aprendizagem, reconhecendo o seu desempenho inadequado, mas sem deixar de salientar os avanços que foram sendo alcançados com a experiência escolar.

As crianças salientam que a causa do baixo desempenho escolar está no próprio aluno. Falta de atenção e indisciplina, são salientadas como comportamentos que interferem no processo ensino-aprendizagem: "Porque eu num sei essas continhas, por causa da bagunça que eu faço na sala e eu num gosto de ficá sentado na carteira, eu fico brincando assim, mexendo, fazendo coisa" (Ramon - Município C ).

A indisciplina é indicada por algumas crianças como o resultado de uma frustração frente às tentativas de aprender. Evidenciam que não transgridem as normas da escola com o intuito de enfrentar os professores em um ato de rebeldia. As conversas e as brincadeiras passam a ser a forma de preencherem o tempo de permanência no ambiente escolar, na medida em que não estão aprendendo. Alguns salientam que não se sentem bem em ficar sem 
aprender nada na sala de aula. O que causa, segundo relatos, angústia e um sentimento de possuir menos valor em relação aos demais colegas.

O relato das crianças demonstra assim uma forma de reação e resistência frente à situação de dificuldades em aprender dentro da sala de aula. Como afirma Müller (2003) tal resistência em ficar calado/a, sentado/a e obediente deve ser melhor compreendida, sem necessariamente ser considerada negativa, ao contrário, em algumas situações a resistência mostra-se como um processo criativo que permite o ser humano se reinventar e se preservar. Contudo, apesar da resistência, as crianças concebiam o rompimento das regras como incorreto.

A vergonha, raiva e desespero são citados por certas crianças como sentimentos experienciados frente ao baixo desempenho acadêmico. Alguns relatos destacam um sofrimento silencioso, como o de Igor (Município C): "Fico com vergonha, ué. Choro em casa sozinho". Tal situação ocorre por acreditarem ser os maiores "culpados" pelas suas dificuldades em aprender, levando ao sofrimento, como o de Ramon (Município C): “ Fico triste e ... amargurado, é amargurado que fala?"

Os sujeitos relataram que se sentem ridicularizados perante os colegas, "Se eu erro na sala os outros fica rindo de mim [...] é muito ruim não saber ler e escrever." (Luana Município C).

Sirino e Cunha (2002) em um estudo desenvolvido com crianças que apresentavam dificuldades escolares encontraram dados que corroboram com os desta pesquisa, indicando o sofrimento das crianças diante das manifestações de preconceitos e estereótipos de seus colegas de sala, docentes ou familiares.

Apesar das frustrações maior parte dos alunos demonstram que frente ao desempenho inadequado, buscam estratégias que possam viabilizar uma melhor aprendizagem. As atitudes mais comumente tomadas são estudar em casa, solicitar auxílio dos pais e serem persistentes ou mesmo desistirem.

Além do apoio dos familiares e do próprio investimento, os relatos evidenciam a necessidade de uma maior atenção por parte das professoras.

Conclui-se que, frente aos baixos desempenhos acadêmicos, os alunos buscam estratégias visando à superação das dificuldades, no entanto, ao fracassarem nas tentativas sentem-se desestimulados a permanecer na sala de aula, o que ocasiona comportamentos de indisciplina e/ou desatenção que, por consequência, dificulta ainda mais sua aprendizagem. Visualiza-se, dessa forma, um círculo vicioso. 
As atitudes tomadas pelos familiares frente ao baixo rendimento acadêmico, com o intuito de auxiliá-los na superação das dificuldades, são: o diálogo, os prêmios e os castigos.

Segundo os alunos, os familiares despendem atenção à escolarização deles, buscam soluções que julgam necessárias para auxiliá-los. Aurora (Município A) afirma que seus familiares dizem a ela: "Que eu tenho que estudar e fazer lição." Contudo, quando os resultados positivos são obtidos, alguns pais não demonstram satisfação e o reconhecimento pelos esforços engendrados pelos (as) alunos (as), como destaca Weslei "Quando eu vô bem? Fala nada não! Só quando tiro D”.

Entretanto, esta constatação não pode ser generalizada, à medida que algumas crianças relatam que os familiares reconhecem as possíveis mudanças positivas em suas aprendizagens.

Em relação às atitudes tomadas pelos professores perante o baixo desempenho acadêmico, é possível apreender dos relatos, que investimentos com o objetivo de atender às especificidades da aprendizagem da criança foram mobilizados. No entanto, atitudes de repressão e ameaças foram conjuntamente adotadas pelas professoras como medidas que visavam à aprendizagem do aluno, como demonstra o depoimento de Weslei "Fala pra eu copiá tudo, senão ela vai me mandá bilhete pra minha mãe [...] Eu tenho medo dela". Denílson (Município B) também evidencia a atitude repressora da professora: "Ela fala que vai dar sapatada quando ninguém fica quieto".

Conforme comentam Lisboa e Koller (2004, p.209), “[...] uma relação conflitante entre professores e alunos pode implicar o comprometimento do sucesso acadêmico e social." Assim, a relação professor aluno pode se configurar em situação de adversidade para o desempenho acadêmico na medida em que não há o reconhecimento de potencialidades e a promoção de autonomia, contribuindo para a instalação de um ambiente ansioso ou em muitos casos, agressivos. Os dados são correlatos da pesquisa desenvolvida por Reis (2002), na qual foi constatado que a importância do aspecto relacional envolve professor e aluno em torno da aprendizagem, gerando condições que podem ser favorecedoras ou não na construção dos conteúdos pela escola.

Bronfenbrenner (1996, p. 47) comenta que a reciprocidade:

[...] motiva os participantes não só a perseverarem, mas também a se engajarem em padrões de interação progressivamente mais complexos.[...] O resultado geralmente é uma aceleração do ritmo e aumento da complexidade dos processos de aprendizagem. 
Neste sentido, o estabelecimento de uma relação recíproca entre professores e alunos pode favorecer a aprendizagem, configurando-se desta forma em recurso para o desempenho acadêmico, na medida em que tende a promover a competência social e desenvolver habilidades cognitivas (LISBOA; KOLLER, 2004).

Atitudes punitivas causam, segundo as crianças, angústia e medo, tornando-se uma ação de influência negativa para a aprendizagem. Tais atitudes podem ser consideradas eficazes ao trabalho docente no sentido de permitir à professora um controle dos comportamentos dos alunos, mas não se evidenciam como eficientes no auxílio à superação das dificuldades apresentadas, aliás, ocasiona exatamente o inverso.

Segundo Bronfenbrenner (1996) a reciprocidade, o afeto e o equilíbrio de poder são imprescindíveis para uma relação diádica efetiva e capaz de gerar desenvolvimento. Os dados permitem afirmar que em diversas vezes as relações entre professora e aluno(a) não se balizava-se nesse tripé, uma vez que as crianças, apesar de gostarem das docentes, sentiam-se ameaçadas ou submetidas a sua hierarquia.

Outra providência da escola frente ao baixo desempenho é o reforço escolar. As percepções infantis sobre as aulas são divergentes, há alunos que consideram o atendimento específico uma atividade prazerosa, eficiente e necessária para a aprendizagem: "Devia ter reforço", conforme comenta Aline (Município B). No entanto, um maior número de alunos destaca o reforço como negativo e apresenta resistência em participar dele de forma assídua.

O relacionamento com a docente é destacado como principal justificativa da nãoadesão às aulas, como destaca Ramon (Município C) “[...] É ruim, a professora briga [...] otro dia eu tava fazendo certinho, tudo certinho e ai ela mandô fazê otra, fiz tudo certinho e ela mandô fazê otra, daí eu fiz, aí eu peguei e fiz certinho e ai ela falô "Agora sim" eu quase xinguei ela, professora chata pra caramba".

O horário é identificado como outro fator que prejudica o andamento eficiente do reforço. Entrar adiantado ou sair mais tarde é indicado como cansativo e desgastante e influencia consideravelmente no desempenho das atividades, além de comprometer a assiduidade às aulas.

\section{Considerações finais}

Pode-se concluir que é necessário engendrar esforços para que se realizem pesquisas que tenham como objetivo ouvir as crianças. Cuidando para modelar o olhar do adulto/pesquisador para que possa perceber as infâncias e os sujeitos que compõem esta 
categoria social de maneira diversa, rompendo com os conceitos tradicionais das pesquisas sobre infância, transgredindo a antiga forma que aprendemos culturalmente a olhar as crianças, ou seja, como seres incompletos, sem fala, um vir a ser e ingênuos.

Importante salientar que os discursos expostos aqui são percepções de um determinado grupo de sujeitos e, devido a sua singularidade, não devem ser tomados como verdades únicas, nem podem ser generalizados por se tratar de estudos pontuais.

De qualquer maneira, as crianças precisam ser compreendidas como sujeitos inseridos no mundo estruturado por relações materiais, sociais, emocionais e cognitivas que organizam suas vidas cotidianas e suas relações com o mundo. Nesse contexto vão construindo suas identidades, não como sujeitos passivos que apenas incorporam a cultura adulta, mas que interpretam essa cultura, interagindo e criando novas formas de compreensão.

As crianças do presente estudo apresentaram uma visão de família enquanto ponto de apoio, suporte e afeto, indiferente do grau de parentesco entre os sujeitos pertencentes a esse grupo. Indicaram-a como uma instituição indispensável para o seu desenvolvimento e esta visão está próxima da concepção que possuem da escola, como um ambiente desejável, importante e lócus de desenvolvimento não só cognitivo, mas social e afetivo.

Quanto as suas concepções sobre o desempenho escolar, as crianças sabem de suas dificuldades e buscam justificá-las de forma pessoal. Apesar de compreenderem que há uma complexa dinâmica para que o ensino-aprendizagem ocorra, indicam-se como grandes culpadas pelo seu "não aprender".

Os dados destacaram também que as crianças concebem a figura da professora como sendo de vital importância, sublinhando o relacionamento afetivo que mantinham.

Os sentimentos experienciados, por todas as crianças, diante da situação do rendimento inadequado são os de angústia e tristeza. Situações que mobilizam sentimentos de medo, vergonha, humilhação e insegurança refletem a hostilidade com que crianças são tratadas na escola.

Apesar das dificuldades, as crianças de todos os municípios pesquisados investiam em sua aprendizagem. Deve-se refletir, contudo, até quando as crianças desses Munícipios engendrarão esses esforços. Até que momento em sua trajetória escolar as crianças ainda buscarão estratégias de superação? Qual atenção é dada ao sofrimento silencioso dessas crianças? O que se tem feito efetivamente a esse respeito?

Pode-se concluir que as crianças ouvidas demonstraram seus sentimentos, concepções, percepções e formas de agir no mundo, obviamente influenciadas pelas construções do mundo 
adulto, mas um olhar peculiar, próprio da interpretação das crianças que vivenciaram e compreenderam esse mundo ao seu modo.

O que nos instiga a compreender esses olhares infantis é a busca em melhor atender as reais necessidades desses alunos. Criar um olhar mais atento, mais alerta ao que o sistema escolar tem produzido ou possa a vir produzir no cotidiano infantil.

A criança possui habilidades que precisam ser potencializadas para o enfrentamento de dificuldades que podem se configurar em fracasso escolar. Neste sentido, atentar para a sua realidade e se voltar para sua trajetória de vida escolar se constituiriam em estratégias eficazes para a identificação das dificuldades que podem influenciar negativamente em seu rendimento e nessa medida, elaborar ações que possam minimizar tais adversidades.

É preciso atentar para a trajetória escolar dos estudantes para impedir que eles cheguem no $5^{\circ}$ ano com defasagens ou mesmo que adquira a concepção de que o percurso da escolarização é penoso.

\section{REFERÊNCIAS}

ASSIS, M. B. A. C. de. Uma análise psicológica do desempenho escolar de crianças de primeira série: aspectos psicodinâmicos e operatórios. 1985. 201f. Tese (Doutorado em Psicologia) - Instituto de Psicologia, Universidade de São Paulo, São Paulo, 1985.

BIASOLI-ALVES, Z. M. M. A pesquisa psicológica: análise de métodos e estratégia na construção de um conhecimento que se pretende científico. In: ROMANELLI, G. (Org.). Diálogos metodológicos sobre prática de pesquisa. Ribeirão Preto: Legis Summa, 1998. p.135-157.

BORBA, A. M. O brincar como um mundo de ser e estar no mundo. In: BRASIL. Ministério da Educação. Coordenação Geral do Ensino Fundamental. Ensino fundamental de nove anos: orientações para a inclusão da criança de seis anos de idade. Brasília: FNDE: Estação Gráfica, 2006. p.33-46.

BROFENBRENNER, U. A teoria bioecológica do desenvolvimento humano. In: BROFENBRENNER, U. Bioecologia do desenvolvimento humano: tornando os seres humanos mais humanos. Tradução de André de Carvalho Barreto. Porto Alegre: ARTMED, 2011. p.43-54.

BROFENBRENNER, U. A ecologia do desenvolvimento humano: experimentos naturais e planejamentos. Porto Alegre: ARTMED, 1996.

BRONFENBRENNER, U.; CECI, S. J. Nature -nurture reconceptualized in developmental perspective: a bioecological model. Psychological Review, Washington, v.110, n.4, p.568586, 1994. 
CARNEIRO, G. R. da S.; MARTINELLI, S. de C.; SISTO, F. F. Autoconceito e dificuldades de aprendizagem na escrita. Psicologia: Reflexão e Crítica, Porto Alegre, v.16, n.3, p.427434, 2003.

CARVALHO, A. M. P. Baixo rendimento escolar: uma visão a partir do professor. In: FUNAYAMA, C. A. R. (Org.). Problemas de aprendizagem: enfoque multidisciplinar. Campinas: Alíneas, 2000. p.115-146.

CHECHIA, V. A. Pais de alunos com sucesso e insucesso escolar: percepções da escola do desempenho escolar dos filhos e do envolvimento com o cotidiano escolar. 2002. Dissertação (Mestrado) - Faculdade de Filosofia Ciências e Letras, Universidade de São Paulo, Ribeirão Preto, 2002.

DELGADO, A. C. C.; MÜLLER, F. Em busca de metodologias investigativas com as crianças e suas culturas. Caderno de pesquisa, São Paulo, v.35, n.125, p.161-179, maio/ago. 2005.

GARCIA, S. C. Rendimento acadêmico, adaptação escolar e autoconceito de alunos de sala de recurso. 2003. Dissertação (Mestrado - Universidade Federal de São Carlos, São Carlos, 2003.

GIRALDI, L. P. B. Os níveis diferenciados de desempenho escolar: analisando estabilidade e mudanças nas concepções e expectativas de professores, familiares e alunos. 2010. $255 \mathrm{f}$. Dissertação (Mestrado em Educação Escolar) - Faculdade de Ciências e Letras, Universidade Estadual Paulista, Araraquara, 2010.

GIMENO-SÁCRISTAN, J. O aluno como invenção. Tradução de Daisy Vaz de Moraes. Porto Alegre: ARTMED, 2005.

LAVILLE, C.; DIONNE, J. A construção do saber: manual de metodologia da pesquisa em ciências humanas. Belo Horizonte: Ed. da UFMG, 1999.

LISBOA, C.; KOLLER, S. H. Interações na escola e processos de aprendizagem: fatores de risco e proteção. In: BORUCHOVITCH, E.; BZUNECK, J. A. (Org.). Aprendizagem: processos psicológicos e o contexto social na escola. Petrópolis: Vozes, 2004. p.201-224.

MANZINI, E. J. A entrevista na pesquisa social. Didática, São Paulo, v.26/27, p.149-158, 1990.

MARCONDES, K. H. B. A relação entre a escola e a família de crianças com baixo rendimento escolar no contexto de progressão continuada. 2006. 285f. Dissertação (Mestrado em Educação Escolar) - Faculdade de Ciências e Letras, Universidade Estadual Paulista, Araraquara, 2006.

MONTEIRO, M. I. Práticas alfabetizadoras e suas relações com o rendimento escolar dos alunos. 2000. 206f. Dissertação (Mestrado em Educação Escolar) - Faculdade de Ciências e Letras, Universidade Estadual Paulista, Araraquara, 2000.

MORAES. A. A. de. Educação infantil: uma análise das concepções de crianças e de sua educação nas produções acadêmicas recentes (1997 - 2002). In: REUNIÃO DA 
ASSOCIAÇÃO NACIONAL DE PÓS- GRADUAÇÃO E PESQUISA EM EDUCAÇÃO, 27., 2004, Caxambu. Anais... Caxambu: ANPED, 2004. Disponível em: <http://27reuniao.anped.org.br/gt07/p073.pdf>. Acesso em: 08 dez. 2016.

MOREIRA, G. M. Recursos e condições adversas na história pregressa de crianças de $4^{\text {a }}$ série do Ensino Fundamental. 2006.298f. Dissertação (Mestrado em Educação Escolar) Faculdade de Ciências e Letras, Universidade Estadual Paulista, Araraquara, 2006.

MÜLLER, F. Infâncias nas vozes das crianças: culturas infantis, trabalho e resistência. In: REUNIÃO DA ASSOCIAÇÃO NACIONAL DE PÓS- GRADUAÇÃO E PESQUISA EM EDUCAÇÃO, 26., 2003, Poços de Caldas. Anais... Poços de Caldas: ANPED, 2003. Disponível em: <http://26reuniao.anped.org.br/>. Acesso em: 08 dez. 2016.

MÜLLER, F.; CARVALHO, A. M. A. Encontros e diálogos: notas introdutórias. In: MÜlleR, F.; CARVALHO, A. M. A. (Org.). Teoria e prática na pesquisa com crianças: diálogos com William Corsaro. São Paulo: Cortez, 2010. p.21-28.

PATTO, M. H. de S. A produção do fracasso escolar: histórias de submissão e rebeldia. São Paulo: T. A. Queiroz, 1996.

PEREIRA, A. S. Sucesso escolar nos meios populares: mobilização pessoal e estratégias familiares. 2005. 213f. Dissertação (Mestrado em Educação) - Pontifícia Universidade Católica, Minas Gerais, 2005.

REIS, R. M. C. Dando voz ao sujeito da aprendizagem: um estudo com crianças no primeiro ano do ensino fundamental. In: REUNIÃO ANUAL DA ANPED, 25., 2002, Caxambu. Anais eletrônicos. Caxambu: ANPED, 2002. Disponível em: <http://25reuniao.anped.org.br/tp25.htm>. Acesso em: 08 dez. 2016.

SANTOS, P. L. dos. Riscos, recursos e fatores de proteção associados ao baixo e alto rendimento acadêmico: estudo comparativo. Ribeirão Preto: Ed. da USP, 2002.

SARMENTO, M. J. Visibilidade social e estudo da infância. In: VASCONCELLOS, M. R. de; SARMENTO, M. J. (Org.). Infância (in)visível. Araraquara: Junqueira \& Marin, 2007. p. $25-49$.

SARMENTO, M. J. Gerações e alteridade: interrogações a partir da Sociologia da Infância. Educação \& Sociedade, Campinas, v.26, n.91, p.361-378, maio/ago. 2005. Disponível em: <http://www.scielo.br/pdf/es/v26n91/a03v2691.pdf >. Acesso em: 22 set. 2009.

SENOS, J. Identidade social, auto-estima e resultados escolares. Análise Psicológica, Lisboa, v.15, n.1, p.123-137, 1997.

SIGOLO, S. R. R. L. Educação de crianças com atraso de desenvolvimento na perspectiva bioecológica de Bronfenbrenner. In: SIGOLO, S. R. R. L.; MANZOLI, L. (Org.). Educação especial face ao desenvolvimento e à inserção social. Araraquara: FCL/UNESP, Laboratório Editoral; São Paulo: Cultura Acadêmica, 2002. p.11-39. 
SIGOLO, S. R. R.; LOLLATO, S. O. Aproximações entre escola e família: um desafio para educadores. In: CHAKUR, C. R. de S. L. Problemas da educação sob o olhar da psicologia. Araraquara: Ed. da UNESP, 2001. p.37-65.

SIRINO, M. F.; CUNHA, B. B. B. Repensando o fracasso escolar: reflexões a partir do discurso do aluno. In: REUNIÃO ANUAL DA ANPED, 25., 2002, Caxambu.

Anais...Caxambu: ANPED, 2002.Disponível em:

<25reuniao.anped.org.br/marisafatimasirinot13.rtf>. Acesso em: 08 dez. 2016.

\section{Como referenciar este artigo}

MOREIRA- MALAGOLLI, Gabriela Maffei.; MARCONDES, Keila Hellen Barbato.; GIRALDI, Luciana Ponce Bellido. Olhares infantis: o baixo desempenho acadêmico, a escola e a família. Doxa: Rev. Bras. Psicol. Educ., Araraquara, v.19, n.1, p. 181-198, jan./jun. 2017. ISSN: $1413-2060$.

Submetido em: 13/02/2017

Aprovado em: 30/03/2017 